\title{
DOSES DE NITROGÊNIO, ESPAÇAMENTOS ENTRELINHAS EM DUAS CULTIVARES DE FEIJOEIRO IRRIGADO NO SISTEMA PLANTIO DIRETO
}

\author{
Mariana Pina da Silva ${ }^{1 *}$, Fabiana Lima Abrantes ${ }^{2}$, Orivaldo $\mathrm{Arf}^{3}$, Marco Eustáquio de Sá ${ }^{3}$, \\ Lilian Christian Domingues de Souza ${ }^{4}$ \\ 1 Docente da Universidade Estadual de Goiás (UEG), Campus de Ipameri - GO. *E-mail: \\ mariana.berti@ueg.br \\ ${ }^{2}$ Docente da UNOESTE, Presidente Prudente - SP. \\ ${ }^{3}$ Docente da Universidade Estadual Paulista (UNESP), Faculdade de Engenharia, Câmpus de Ilha Solteira - \\ SP. \\ ${ }^{4}$ Docente na Faculdade de Ciências Sociais de Guarantã do Norte - MT.
}

RESUMO: A cultura do feijoeiro tem se apresentado na região de cerrado como uma excelente opção de cultivo no período de inverno, com irrigação. O trabalho foi desenvolvido no ano de 2009, com o objetivo de avaliar em duas cultivares de feijoeiro (Pérola e Juriti) cultivadas em sucessão ao milho no sistema plantio direto no período "de inverno", o efeito de espaçamentos entrelinhas $(0,40 ; 0,50$ e $0,60 \mathrm{~m})$ e de doses de $\mathrm{N}$ em cobertura $\left(0,35,70,105\right.$ e $\left.140 \mathrm{~kg} \mathrm{ha}^{-1}\right)$ visando o crescimento e a produtividade de grãos de feijão. O delineamento utilizado foi em blocos casualizados, em um esquema de parcelas subdivididas, com quatro repetições. $\mathrm{O}$ espaçamento de $0,40 \mathrm{~m}$ entrelinhas proporciona maior produtividade de grãos em ambas as cultivares analisadas, quando se mantêm a população de plantas indicada para o habito de crescimento.O fornecimento de doses crescentes de $\mathrm{N}$ em cobertura proporciona aumento na produtividade de grãos em ambas as cultivares estudadas.

Palavras-chave: Adubação. cv. Pérola. cv. Juriti. Phaseolus vulgaris. População de plantas.

\section{NITROGEN LEVELS AND ROW SPACING IN TWO COMMON BEAN CULTIVARS IRRIGATED IN NO-TILLAGE SYSTEM}

\begin{abstract}
The common bean crop has been performing in the region as an excellent choice for cultivation during "winter", with irrigation. The study was conducted in 2009, with the aim of evaluating in two common bean cultivars grown in succession to corn in notillage system in the "winter" the effect of row spacing $(0.40,0.50$ and $0.60 \mathrm{~m})$ and $\mathrm{N}$ fertilization $\left(0,35,70,105\right.$ and $\left.140 \mathrm{~kg} \mathrm{ha}^{-1}\right)$ as the productivity of seeds. The spacing between rows of $0.40 \mathrm{~m}$ provides the highest grain yield in both cultivars studied, when keeping the population of plants suitable for the growth habit. The provision of increasing levels of $\mathrm{N}$ in coverage provides increase in seed yield in both cultivars.
\end{abstract}

Key words: Fertilization. cv. Pérola. cv. Juriti. Phaseolus vulgaris. Plant population. 


\section{INTRODUÇÃO}

O feijoeiro é uma espécie de planta que, geralmente, possui grande capacidade de compensação, ou seja, ocupa os espaços vazios numa área em que o número de plantas estabelecido é menor que o recomendado. Esta compensação das falhas, entretanto, pode ser maior ou menor, dependendo das características da cultivar. As cultivares com plantas arbustivas e as de crescimento determinado ramificam menos e, portanto, a capacidade de compensação é menor (DOURADO NETO e FANCELLI, 2000)

A cultivar Pérola, por apresentar porte mais prostrado (tipo III), tende a fechar mais rápido as entrelinhas que uma cultivar de porte mais ereto como IPR- Juriti (tipo II). Sob o ponto de vista fisiológico, com o fechamento mais rápido das entrelinhas, há tendência em ocorrer uma maior competição das plantas por luz. Por isso, há o estiolamento das plantas, que resulta em maior crescimento que pode ser verificado pelo maior número de ramos e consequentemente pela maior produtividade. Esse fato é confirmado por Morais et al. (2001) que verificaram que para o caráter fechamento entrelinhas a cultivar e espaçamento tem forte influência nessa característica.

As respostas das plantas de feijão às alterações nas condições de competição por recursos ambientais, como radiação solar, água e nutrientes, geradas por modificações na população e espaçamento de plantas, apresentam estreita relação com o tipo e hábito de crescimento da cultivar (NIENHUIS e SINGH, 1985). Segundo Almeida e Sangoi (1994), a cultivar de feijão através do seu hábito de crescimento e da capacidade de compensar o espaço disponível, é fator primordial a ser considerado na definição da população e espaçamento de plantas adequado.

Fronza et al. (1994), utilizando duas cultivares de feijoeiro do tipo II, com espaçamentos entrelinhas variando de 0,20 a $0,50 \mathrm{~m}$, observaram que a máxima eficiência técnica para o rendimento de grãos ocorreu no espaçamento de $0,33 \mathrm{~m}$ entrelinhas. No Estado de São Paulo, Almeida et al. (1975), utilizando a cultivar Carioca, com hábito indeterminado de crescimento tipo III, compararam os espaçamentos de 0,30 e 0,40 m entrelinhas, concluindo que se deve optar pelos espaçamentos maiores para obtenção de maiores produtividades. Estes resultados sugerem que, para as cultivares de hábito de crescimento indeterminado tipo III, prostradas, há uma tendência de obtenção de maiores produtividades com o uso de espaçamentos maiores, mantendo-se o número usual de plantas por metro.

No que diz respeito à adubação nitrogenada, Barbosa Filho e Silva (2000) argumentam que cultivares com outros hábitos de crescimento e exigências nutricionais distintas devem ser mais bem estudados quanto à adubação nitrogenada, já que a cultivar Aporé (hábito II/III) apresentou melhor eficiência no uso de nutrientes em relação a cultivar Carioca (tipo III). Recomendações específicas poderão aperfeiçoar o uso de fertilizantes nitrogenados, reduzir o custo de produção e evitar problemas de contaminação ambiental provocados pelo uso excessivo de fertilizantes.

Cultura Agronômica, Ilha Solteira, v.27, n.2, p.190-204, 2018 
Assim, o trabalho teve como objetivo avaliar em feijoeiro cultivado em sucessão ao milho em sistema plantio direto no período de inverno, o efeito de espaçamentos entrelinhas e doses de $\mathrm{N}$ em cobertura no desenvolvimento e produtividade de grãos das cultivares Pérola e Juriti.

\section{MATERIAL E MÉTODOS}

O trabalho foi conduzido durante o ano de 2009 no município de Selvíria - MS, apresentando como coordenadas geográficas $51^{\circ} 22^{\prime} \mathrm{W}$ e $20^{\circ} 22^{\prime} \mathrm{S}$ e altitude de $335 \mathrm{~m}$. O clima é do tipo Aw, segundo a classificação de Köeppen, definido como tropical úmido com estação chuvosa no verão e seca no inverno. Segundo Centurion (1982), a temperatura média anual é de aproximadamente $25^{\circ} \mathrm{C}$, precipitação total anual de $1.330 \mathrm{~mm}$ e a média anual de umidade relativa do ar de 66\%; os dados climáticos durante a condução do experimento estão apresentados na Figura 1.

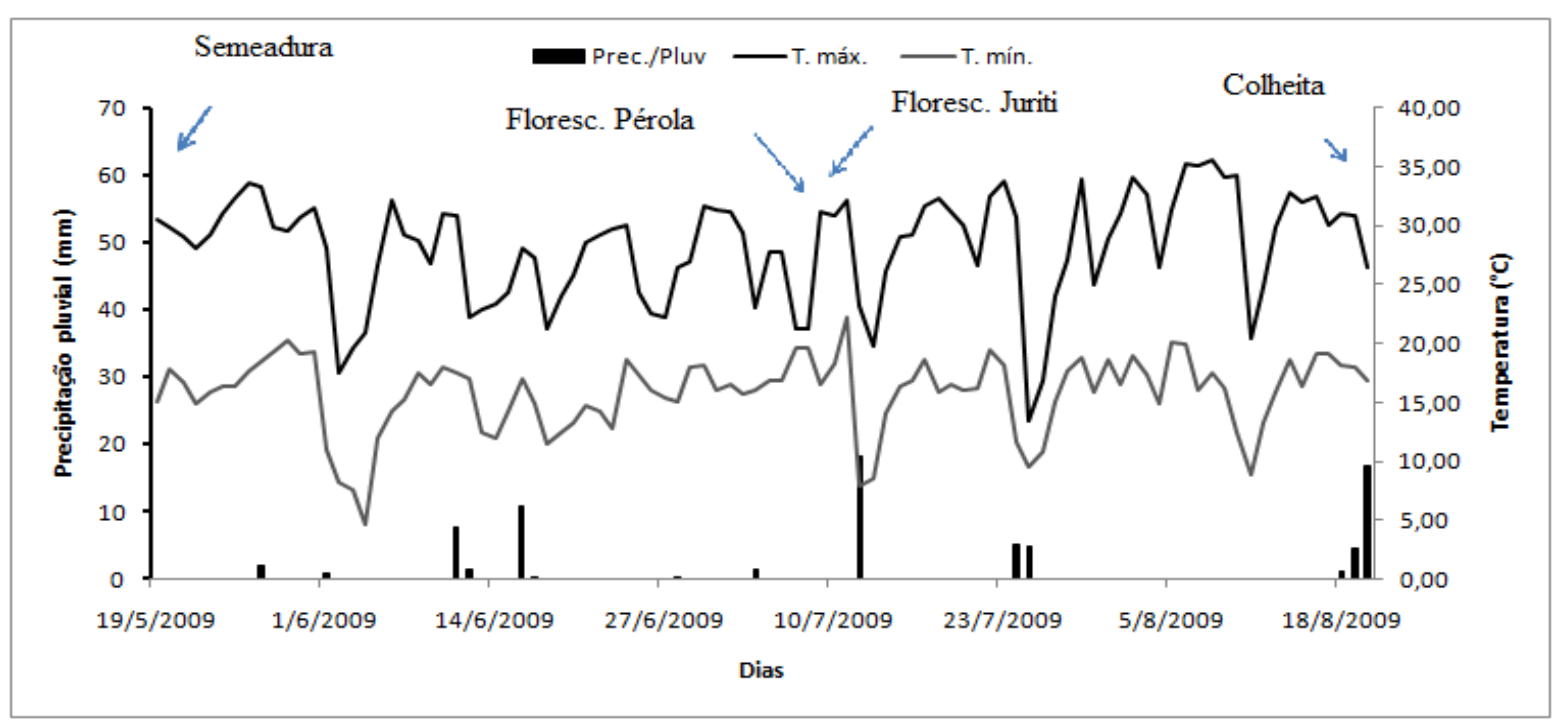

Figura 1. Precipitação pluvial $(\mathrm{mm})$ acumulada, Valores diários médios de temperatura máxima e mínima $\left({ }^{\circ} \mathrm{C}\right)$, coletados durante a condução do experimento. Selvíria - MS, 2009.

O solo do local é considerado de acordo com a classificação da Embrapa (2006), como Latossolo Vermelho Distrófico típico argiloso.

Antes da instalação do experimento foi coletada na profundidade de $0-0,20 \mathrm{~m}$ uma amostra representativa da área experimental para análise química do solo. Os resultados da análise foram os seguintes: Matéria orgânica $28 \mathrm{~g} \mathrm{dm}^{-3} ; \mathrm{pH} \mathrm{CaCl}_{2} 5,3 ; \mathrm{P}$ resina $15 \mathrm{mg} \mathrm{dm}^{-3}$;

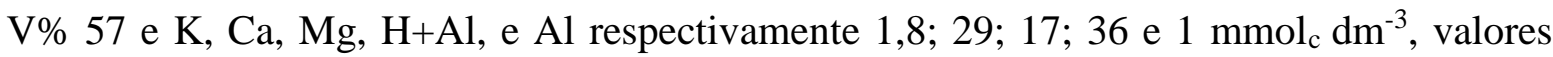
considerados adequados para a cultura (MASCARENHAS e TANAKA, 1997).

O delineamento experimental utilizado foi o de blocos casualizados, em um esquema de parcelas subdivididas, considerando os três espaçamentos como parcela e a adubação nitrogenada (cinco doses) como sub-parcela. Os tratamentos foram constituídos por duas cultivares (Pérola e Juriti) de hábito de crescimento diferente, tipo III e II, respectivamente, 
três espaçamentos entrelinhas $(0,40 ; 0,50$ e $0,60 \mathrm{~m})$ e cinco doses de $\mathrm{N}$ em cobertura $(0,35$, 70,105 e $\left.140 \mathrm{~kg} \mathrm{ha}^{-1}\right)$.

A parcela experimental foi constituída de cinco linhas de seis metros de comprimento, sendo consideradas como parcela as três linhas centrais, desprezando-se $0,5 \mathrm{~m}$ em ambas as extremidades de cada linha.

As irrigações foram realizadas com uma lâmina de água de $13 \mathrm{~mm}$ nos períodos de maior exigência da cultura $\left(\mathrm{R}_{5} \mathrm{a}_{7}\right)$ por um sistema de irrigação por aspersão do tipo pivô central. Para determinar a quantidade e o momento de irrigação foram utilizados dados de evaporação de água (ECA) obtidos diariamente do tanque Classe A instalado no Posto Meteorológico da Fazenda de Ensino e Pesquisa distante aproximadamente $500 \mathrm{~m}$ da área experimental. No manejo de água durante o desenvolvimento da cultura foram utilizados valores de Kc semelhantes aos recomendados por Doorenbos e Kassan (1988) e de acordo com os estádios fenológicos da planta de feijão descritos por Fernandez et al. (1985), ou seja para as fases de $\mathrm{V}_{0}-\mathrm{V}_{2}(\mathrm{Kc}=0,30)$, de $\mathrm{V}_{3}-\mathrm{V}_{4}(\mathrm{Kc}=0,70)$, de $\mathrm{R}_{5}-\mathrm{R}_{7}(\mathrm{Kc}=1,05), \mathrm{R}_{8}(0,75)$ e $\mathrm{R}_{9}$ $(0,25)$.

A cultura foi instalada no dia 19 de maio de 2009 com irrigação por pivô central em sistema plantio direto, sendo o milho a cultura antecessora. A dessecação da área foi efetuada com glyphosate (1560 $\mathrm{g} \mathrm{ha}^{-1}$ do ingrediente ativo) e posteriormente os restos culturais foram manejados com triturador mecânico, com o objetivo de facilitar a demarcação das parcelas. A semeadura foi realizada mecanicamente utilizando semeadora regulada para depositar sementes em dobro da necessidade para que posteriormente as parcelas fossem desbastadas atingindo a população desejada para cada cultivar. Para o tratamento de sementes utilizou-se carboxin + thiram $(200+200 \mathrm{~g}$ do i.a. para $100 \mathrm{~kg}$ de sementes). Foram aplicados na adubação básica de semeadura $250 \mathrm{~kg} \mathrm{ha}^{-1}$ da fórmula 8-2816, ajustando-se a distribuição do fertilizante para cada espaçamento, de maneira que todos os tratamentos recebessem a mesma quantidade de fertilizante na semeadura. A abertura dos sulcos e a distribuição do fertilizante foram realizadas com semeadora especifica para o sistema plantio direto, com mecanismo sulcador de hastes. Após a semeadura a área foi irrigada para promover a germinação das sementes. A emergência ocorreu no dia 27 de maio de 2009.

Dezenove dias após a emergência, foi realizado desbaste para atingir a população de plantas desejada (166.600 plantas ha $^{-1}$ para a cultivar Pérola e 200.000 plantas ha hara a $^{-1}$ para cultivar Juriti), para todos os espaçamentos utilizados.

O controle de plantas daninhas foi realizado aos 23 e 30 dias após a emergência das plantas (DAE), utilizando fomesafen (200 $\mathrm{g} \mathrm{ha}^{-1}$ do i. a.) e fenoxaprope-p-etílico + cletodim $\left(25+25 \mathrm{~g} \mathrm{ha}^{-1}\right.$ do i. a.), respectivamente. Para o controle das pragas foi realizada a aplicação de deltametrina+triazofós $\left(4+140 \mathrm{~g} \mathrm{ha}^{-1}\right.$ do i. a.) aos 26 e 40 DAE e imidacloprid+beta-ciflutrina $\left(50+6,25 \mathrm{~g} \mathrm{ha}^{-1}\right.$ do i. a.) aos 56 DAE. Para o controle das 
doenças foi utilizado o fungicida mancozeb $\left(800 \mathrm{~g} \mathrm{ha}^{-1}\right.$ do i.a.) aplicado aos 26,40 e 56 DAE.

$\mathrm{Na}$ fase $\mathrm{V}_{4-3}$ de desenvolvimento do feijoeiro, aos 21 dias após a emergência das plantas, foi realizada a adubação nitrogenada de cobertura, manualmente, nas doses de 35, 70,105 e $140 \mathrm{~kg} \mathrm{ha}^{-1}$, utilizando-se como fonte a uréia. Após a aplicação foi efetuada irrigação com lâmina de água de $13 \mathrm{~mm}$, com o objetivo de minimizar as perdas por volatilização.

No período de florescimento pleno (44 DAE) foram coletadas 10 plantas em uma das linhas de cada parcela experimental para determinação da massa da matéria seca por planta e o terceiro trifólio de 10 plantas para determinação dos teores de $\mathrm{N}$, conforme metodologia descrita por Malavolta et al. (1997).

Por ocasião da colheita, realizada aos 85 DAE (20 de agosto de 2009) foi avaliada a população final de plantas de feijoeiro por meio da contagem das plantas em duas linhas de $5 \mathrm{~m}$ na parcela útil.

No momento da colheita foram coletadas 10 plantas seguidas, na mesma linha utilizada para avaliação da massa da matéria seca de plantas e levadas para avaliação no laboratório para determinação das seguintes características: número de vagens por planta, número de sementes por vagem e massa de 100 sementes. A produtividade de sementes foi determinada em duas linhas de cinco metros, dentro da parcela útil. As plantas foram arrancadas manualmente e colocadas em sacos de juta devidamente etiquetados e levados para secagem natural em terreiro. Posteriormente, realizou-se a trilha mecânica e as sementes de cada parcela foram colocadas em sacos de papel, pesadas, determinando-se o teor de umidade das mesmas, sendo os resultados de produtividade determinados em $\mathrm{kg} \mathrm{ha}^{-1}$ (13\% base úmida).

Os dados obtidos foram submetidos à análise de variância e ao teste $\mathrm{F}$, e as médias comparadas pelo teste de Tukey a 5\% de significância utilizando-se o programa SISVAR 5.3 (FERREIRA, 2008). Para as doses de N, aplicaram-se análises de regressão.

\section{RESULTADOS E DISCUSSÃO}

A população final da cultivar Juriti ficou em 191.300 plantas $\mathrm{ha}^{-1}$ e a cultivar Pérola em 150.300 plantas ha $^{-1}$. Verificou-se nas duas cultivares redução na população em relação à condição inicial de 9,8 \% para a cultivar Pérola enquanto que para a cultivar Juriti apenas $4,4 \%$.

Verifica-se na Tabela 2, o desdobramento da interação significativa entre espaçamentos entrelinhas e doses de $\mathrm{N}$ em cobertura para massa da matéria seca de plantas de feijoeiro cv Pérola.

Para a cv. Pérola verifica-se que para o espaçamento de $0,50 \mathrm{~m}$ os dados se ajustaram a uma equação linear $\mathrm{y}=7,64-0,016 \mathrm{x}\left(\mathrm{R}^{2}=0,90\right)$, demonstrando que o aumento de $\mathrm{N}$ em 
cobertura propiciou aumento na massa seca das plantas de feijoeiro. Estes resultados, concordam com os obtidos por Arf et al. (2003) que também observaram aumento da produção de massa da matéria seca da parte aérea com aumento nas doses de N. Para o espaçamento de $0,60 \mathrm{~m}$ os dados se ajustaram a uma função quadrática $\mathrm{y}=5,80+0,025 \mathrm{x}-$ $000013 \mathrm{x}^{2}\left(\mathrm{R}^{2}=0,45\right)$ atingindo um máximo com a dose de $96,15 \mathrm{~kg} \mathrm{ha}^{-1}$ de nitrogênio. Para o espaçamento de $0,40 \mathrm{~m}$ a regressão não foi significativa (Tabela 2).

Tabela 1. Valores médios e valores de F para massa da matéria seca e teor foliar de $\mathrm{N}$ em plantas de feijoeiro, cultivares Pérola e Juriti em função de espaçamentos entrelinhas e doses de nitrogênio em cobertura no período de inverno.

\begin{tabular}{|c|c|c|c|c|}
\hline \multirow[t]{2}{*}{ Causa de Variação } & \multicolumn{2}{|c|}{$\begin{array}{l}\text { Massa da matéria seca } \\
\qquad\left(\mathrm{g} \text { planta }^{-1}\right)\end{array}$} & \multicolumn{2}{|c|}{$\begin{array}{l}\text { Teor foliar de } \mathrm{N} \\
\qquad\left(\mathrm{g} \mathrm{kg}^{-1}\right)\end{array}$} \\
\hline & Pérola & Juriti & Pérola & Juriti \\
\hline \multicolumn{5}{|l|}{ Espaçamento (m) } \\
\hline 0,4 & 5,91 & 5,74 & 42,12 & 41,63 \\
\hline 0,5 & 6,53 & 5,00 & 40,85 & 40,40 \\
\hline 0,6 & 6,55 & 5,21 & 40,89 & 41,59 \\
\hline $\mathrm{CV}(\%)$ & 2,76 & 8,92 & 8,66 & 7,28 \\
\hline \multicolumn{5}{|c|}{ Nitrogênio em cobertura $\left(\mathrm{kg} \mathrm{ha}^{-1}\right)$} \\
\hline 0 & 6,63 & 4,63 & 41,19 & $42,60^{(1)}$ \\
\hline 35 & 6,08 & 4,90 & 40,43 & 41,76 \\
\hline 70 & 6,56 & 5,19 & 41,13 & 39,18 \\
\hline 105 & 6,28 & 6,11 & 42,00 & 40,34 \\
\hline 140 & 6,10 & 5,74 & 41,70 & 42,14 \\
\hline $\mathrm{CV}(\%)$ & 8,57 & 10,83 & 8,72 & 6,98 \\
\hline \multicolumn{5}{|c|}{ Teste de F } \\
\hline Espaçamento (a) & $85,79 * *$ & $12,82 \mathrm{~ns}$ & $0,810^{\mathrm{ns}}$ & $1,08^{\mathrm{ns}}$ \\
\hline Nitrogênio em cobertura (b) & $2,61^{\mathrm{ns}}$ & $13,36^{* *}$ & $0,33^{\text {ns }}$ & $2,89 *$ \\
\hline $\mathrm{a} \times \mathrm{b}$ & $9,48 * *$ & $4,09 * *$ & $0,77^{\mathrm{ns}}$ & $1,18^{\mathrm{ns}}$ \\
\hline
\end{tabular}

Tabela 2. Desdobramento da interação significativa entre espaçamentos entrelinhas $x$ doses de nitrogênio em cobertura para massa da matéria seca $\left(\mathrm{g} \mathrm{planta}^{-1}\right)$ de plantas de feijoeiro cultivar Pérola.

\begin{tabular}{ccccccc}
\hline \multirow{2}{*}{ Espaçamento $(\mathrm{m})$} & \multicolumn{6}{c}{ Doses de Nitrogênio $\left(\mathrm{kg} \mathrm{ha}^{-1}\right)$} \\
\cline { 2 - 7 } & 0 & 35 & 70 & 105 & 140 & \\
\hline 0,4 & $6,15 \mathrm{~b}$ & $5,05 \mathrm{~b}$ & $6,00 \mathrm{~b}$ & $6,5 \mathrm{a}$ & $5,85 \mathrm{~b}$ & $\mathrm{~ns}$ \\
0,5 & $7,95 \mathrm{a}$ & $6,88 \mathrm{a}$ & $6,15 \mathrm{~b}$ & $6,1 \mathrm{a}$ & $5,58 \mathrm{~b}$ & $\mathrm{RL} * *$ \\
0,6 & $5,78 \mathrm{~b}$ & $6,33 \mathrm{a}$ & $7,53 \mathrm{a}$ & $6,23 \mathrm{a}$ & $6,88 \mathrm{a}$ & $\mathrm{RQ}^{*}$ \\
\hline DMS 0,85 & & & & &
\end{tabular}

Médias seguidas da mesma letra minúscula na coluna não diferem entre si pelo teste de tukey ao nível de 5\% de probabilidade. ${ }^{* *} \mathrm{p}<0,01 ;{ }^{*} \mathrm{p}<0,05$ e ${ }^{\mathrm{ns}}$ não significativo. $\mathrm{RL}=$ regressão linear; $\mathrm{RQ}=$ regressão quadrática.

Cultura Agronômica, Ilha Solteira, v.27, n.2, p.190-204, 2018 
Também ocorreu interação significativa entre espaçamentos entrelinhas e doses de $\mathrm{N}$ em cobertura para massa da matéria seca de plantas de feijoeiro cv. Juriti (Tabela 3).

Tabela 3. Desdobramento da interação significativa entre espaçamentos entrelinhas $\mathrm{x}$ doses de nitrogênio em cobertura para massa da matéria seca de plantas (g planta $\left.{ }^{-1}\right)$ de feijoeiro cultivar Juriti.

\begin{tabular}{ccccccc}
\hline \multirow{2}{*}{ Espaçamento $(\mathrm{m})$} & \multicolumn{6}{c}{ Doses de Nitrogênio $\left(\mathrm{kg} \mathrm{ha}^{-1}\right)$} \\
\cline { 2 - 7 } & 0 & 35 & 70 & 105 & 140 & \\
\hline 0,4 & $5,23 \mathrm{a}$ & $4,93 \mathrm{a}$ & $5,90 \mathrm{a}$ & $6,65 \mathrm{a}$ & $5,98 \mathrm{a}$ & $\mathrm{RL}^{* *}$ \\
0,5 & $3,68 \mathrm{~b}$ & $4,98 \mathrm{a}$ & $4,20 \mathrm{~b}$ & $6,40 \mathrm{a}$ & $5,75 \mathrm{a}$ & $\mathrm{RL}^{* *}$ \\
0,6 & $4,98 \mathrm{a}$ & $4,80 \mathrm{a}$ & $5,48 \mathrm{a}$ & $5,28 \mathrm{~b}$ & $5,50 \mathrm{a}$ & $\mathrm{RL}^{*}$ \\
\hline
\end{tabular}

DMS 0,96

Médias seguidas da mesma letra minúscula na coluna não diferem entre si pelo teste de tukey ao nível de 5\% de probabilidade. ${ }^{* *} \mathrm{p}<0,01 ;{ }^{*} \mathrm{p}<0,05 . \mathrm{RL}=$ regressão linear.

Observa-se que para todos os espaçamentos da cultivar Juriti os dados se ajustaram a equações lineares: $\mathrm{y}=5,09+0,0092 \mathrm{x}\left(\mathrm{r}^{2}=0,56\right)$ para o espaçamento $0,40 \mathrm{~m}, \mathrm{y}=3,89+0$, 0016x $\left(\mathrm{r}^{2}=0,63\right)$ para o espaçamento $0,50 \mathrm{~m}$ e $\mathrm{y}=4,90+0,0044 \mathrm{x}\left(\mathrm{r}^{2}=0,61\right)$ para o espaçamento de $0,60 \mathrm{~m}$.

Nas Tabelas 2 e 3, verifica-se maior produção na massa da matéria seca da cultivar Perola (tipo III), esse fato pode ser atribuído ao crescimento indeterminado prostrado que apresenta maior número de ramos e ramificações mais abertas que proporcionam uma cobertura mais rápida da área quando em condições hídricas adequadas como as que ocorreram durante o período, ou também pelo conteúdo de carboidrato nas diversas partes plantas de feijão que pode variar conforme o seu estado de desenvolvimento e, até certo ponto, com o seu habito de crescimento (PORTES,1996).

Constatou-se também, que com o aumento do espaçamento entrelinhas houve aumento na quantidade de massa de matéria seca produzida pela planta de habito de crescimento tipo III, ocorrendo o inverso para plantas do tipo II. Essa afirmação está de acordo com os estudos de Shimada et al. (2000) em plantas de hábitos de crescimento tipo II e III. Arf et al. (1996) observaram resultados semelhantes e salientaram que as cultivares de feijão do tipo II , possuem massa individual menor por serem afetadas pela competição por luz,água ,nutrientes e espaço físico.

Para teores foliares de nitrogênio da cultivar Pérola (Tabela 1), verifica-se que não houve diferença significativa entre os tratamentos. É importante salientar, entretanto, que os teores de nitrogênio na folha verificados em todos os tratamentos estão na faixa considerada adequada para a cultura (30 a $50 \mathrm{~g} \mathrm{~kg}^{-1}$ ), de acordo com Ambrosano et al. (1997). Mesmo na testemunha, sem aplicação de nitrogênio em cobertura, o teor nas folhas estava adequado, possivelmente devido à fixação simbiótica com bactérias nativas fixadoras de nitrogênio, somado ao nitrogênio proveniente da mineralização da matéria orgânica do solo e o fornecido por ocasião da semeadura. O mesmo não aconteceu em estudo semelhante de 
Silveira e Damasceno (1993) que avaliaram a aplicação de doses de $\mathrm{N}$ na cultura do feijoeiro irrigado por aspersão, e verificaram aumento linear do teor de $\mathrm{N}$ na parte aérea da planta de feijão Carioca (tipo III) com o aumento da dose desse nutriente aplicada ao solo.

Em relação a cultivar Juriti (Tabela 1) o teor de $\mathrm{N}$ foi influenciado pelas doses de adubação nitrogenada em cobertura sendo que os dados se ajustaram a uma função quadrática $\mathrm{y}=42,96-0,080 \mathrm{x}+0,0005 \mathrm{x}^{2}\left(\mathrm{R}^{2}=0,80\right)$. Por essa equação tem se um aumento no teor de $\mathrm{N}$ foliar em função das doses, atingindo um máximo com a dose de $80 \mathrm{~kg} \mathrm{ha}^{-1} \mathrm{de}$ N. Coelho et al. (2001) também observaram efeito da aplicação de N sobre o teor de nitrogênio foliar da cultura do feijoeiro do tipo II (cultivar Xamego).

Na cultivar Juriti (Tabela 4) observa-se que para número de vagens por planta os dados se ajustaram a uma função quadrática.

Tabela 4.Valores médios e valores de F para número de vagens por planta (NVP), número de grãos por vagem (NSV), massa de 100 grãos (M100) e produtividade de feijoeiro, cultivares Pérola e Juriti, em função de espaçamentos entrelinhas e aplicação de nitrogênio em cobertura no período de inverno.

\begin{tabular}{|c|c|c|c|c|c|c|c|c|}
\hline \multirow{2}{*}{$\begin{array}{l}\text { Causa de } \\
\text { variação }\end{array}$} & \multicolumn{2}{|c|}{ NVP } & \multicolumn{2}{|c|}{ NSV } & \multicolumn{2}{|c|}{$\mathrm{M} 100(\mathrm{~g})$} & \multicolumn{2}{|c|}{ Produt. $\left(\mathrm{kg} \mathrm{ha}^{-1}\right)$} \\
\hline & Pérola & Juriti & Pérola & Juriti & Pérola & Juriti & Pérola & Juriti \\
\hline \multicolumn{9}{|l|}{ Espaç. (m) } \\
\hline 0,4 & 14,24 & 13,62 & 4,96ab & 4,67 & 25,56 & 22,59 & $4105 a$ & $3243 a$ \\
\hline 0,5 & 10,57 & 13,52 & $4,78 b$ & 4,60 & 25,03 & 22,93 & $2953 b$ & $2739 a b$ \\
\hline 0,6 & 12,65 & 12,79 & $5,00 \mathrm{a}$ & 4,62 & 25,1 & 21,4 & $2504 \mathrm{c}$ & $1854 b$ \\
\hline $\mathrm{CV}(\%)$ & 14,58 & 9,16 & 3,93 & 11,34 & 2,71 & 5,32 & 17,85 & 37,59 \\
\hline \multicolumn{9}{|l|}{$\bar{N}\left(\mathrm{~kg} \mathrm{ha}^{-1}\right)$} \\
\hline 0 & 11,88 & $11,81^{(2)}$ & 4,72 & 4,61 & 24,65 & 21,73 & $2794^{(3)}$ & $2270^{(4)}$ \\
\hline 35 & 11,31 & 13,07 & 4,92 & 4,89 & 25,42 & 22,89 & 2827 & 2394 \\
\hline 70 & 12,72 & 14,17 & 5,00 & 4,71 & 25,48 & 22,45 & 3318 & 2686 \\
\hline 105 & 11,94 & 13,79 & 4,98 & 4,77 & 25,5 & 22,56 & 3416 & 2980 \\
\hline 140 & 14,59 & 13,71 & 4,94 & 4,52 & 25,11 & 21,9 & 3581 & 2715 \\
\hline $\mathrm{CV}(\%)$ & 13,67 & 12,88 & 8,78 & 7,11 & 2,21 & 3,21 & 18,78 & 17,81 \\
\hline \multicolumn{9}{|l|}{ Teste F } \\
\hline Espaç.(a) & $20,38 * *$ & $2,79^{\mathrm{ns}}$ & $7,73^{*}$ & $0,66^{\mathrm{ns}}$ & $3,55 \mathrm{~ns}$ & $9,23^{*}$ & $42,18 * *$ & $10,25 *$ \\
\hline Nitrog.(b) & $6,74 * *$ & $3,51^{*}$ & $0,82^{\mathrm{ns}}$ & $2,28^{\mathrm{ns}}$ & $5,02 * *$ & $5,39 * *$ & $4,26 * *$ & $4,39 * *$ \\
\hline$a \times b$ & $3,35 * *$ & $1,53^{\mathrm{ns}}$ & $1,19^{\mathrm{ns}}$ & $0,75^{\mathrm{ns}}$ & $11,02 * *$ & $3,99 * *$ & $1,16^{\mathrm{ns}}$ & $0,69^{\text {ns }}$ \\
\hline
\end{tabular}

Médias seguidas da mesma letra minúscula na coluna não diferem entre si pelo teste de tukey ao nível de 5\% de probabilidade. ${ }^{* *} \mathrm{p}<0,01 ; * \mathrm{p}<0,05$ e ${ }^{\mathrm{ns}}$ não significativo. ${ }^{(2)} \mathrm{y}=11,81+0,047 \mathrm{x}-0,00024 \mathrm{x}^{2}\left(\mathrm{R}^{2}=0,95\right) .{ }^{(3)} \mathrm{y}=$ $2754,88=6,17 x\left(\mathrm{r}^{2}=0,92\right) \cdot{ }^{(4)} \mathrm{y}=2313,56+4,22 \mathrm{x}\left(\mathrm{r}^{2}=0,69\right)$

Por essa equação atinge-se um aumento máximo com a dose de 97,92 $\mathrm{kg} \mathrm{ha}^{-1}$ de $\mathrm{N}$, para depois ocorrer um decréscimo em doses maiores. Os resultados estão de acordo com os reportados por Coelho et al. (2001) que observaram que a aplicação de $\mathrm{N}$ aumentou o 
número de vagens por planta do cultivar Xamego (tipo II) e por Cunha et al. (2011) em plantas de feijoeiro do tipo II (BRS Supremo).

Houve interação significativa para número de vagem por planta entre espaçamentos entrelinhas e doses de $\mathrm{N}$ em cobertura para feijoeiro cv. Pérola e o desdobramento da interação está apresentado na Tabela 5. Pelos dados verifica-se que para o espaçamento de $0,40 \mathrm{~m}$ os dados se ajustaram a uma função quadrática $\mathrm{y}=13,99-0,059 \mathrm{x}+0,0006 \mathrm{x}^{2}$ $\left(\mathrm{R}^{2}=0,57\right)$ atingindo um máximo com a dose de $49,16 \mathrm{~kg} \mathrm{ha}^{-1}$ de $\mathrm{N}$. Para o espaçamento de $0,60 \mathrm{~m}$ os dados se ajustaram a uma equação linear $\mathrm{y}=10,66+0,028 \mathrm{x}\left(\mathrm{r}^{2}=0,94\right)$.

Tabela 5. Desdobramento da interação significativa entre espaçamentos entrelinhas $x$ doses de nitrogênio em cobertura para número de vagem por planta de feijoeiro cultivar Pérola.

\begin{tabular}{|c|c|c|c|c|c|c|}
\hline \multirow[b]{2}{*}{ Espaçamento (m) } & \multicolumn{6}{|c|}{ Doses de Nitrogênio $\left(\mathrm{kg} \mathrm{ha}^{-1}\right)$} \\
\hline & 0 & 35 & 70 & 105 & 140 & \\
\hline 0,4 & $13,44 a$ & $13,20^{\mathrm{a}}$ & $14,35 \mathrm{a}$ & $11,68 \mathrm{ab}$ & $18,52 \mathrm{a}$ & $\mathrm{RQ}^{* *}$ \\
\hline 0,5 & $11,05 \mathrm{a}$ & $9,56 b$ & $11,42 \mathrm{a}$ & $10,43 b$ & $10,40 \mathrm{c}$ & $\mathrm{ns}$ \\
\hline 0,6 & $11,15 \mathrm{a}$ & $11,18 \mathrm{ab}$ & $12,37 \mathrm{a}$ & $13,70 \mathrm{a}$ & $14,86 b$ & $\mathrm{RL} * *$ \\
\hline
\end{tabular}

Médias seguidas da mesma letra minúscula na coluna não diferem entre si pelo teste de tukey ao nível de 5\% de probabilidade. ${ }^{* *} \mathrm{p}<0,01$ e ${ }^{\text {ns }}$ não significativo. $\mathrm{RL}=$ regressão linear; $\mathrm{RQ}=$ regressão quadrática.

Para o desdobramento espaçamento entrelinhas dentro de doses de $\mathrm{N}$ observa-se de maneira geral que o espaçamento de 0,50 e 0,60 m apresentaram menor número de vagem por planta em relação ao espaçamento de $0,40 \mathrm{~m}$. Este fato é explicado devido a um maior número de plantas na linha dos espaçamentos maiores (quando mantido a mesma população em todos os espaçamentos) que faz com que reduza o número de vagens por planta. Os dados concordam com os obtidos por Teixeira et al. (2000) que observaram na cultivar Pérola (tipo III) que o aumento do número de sementes por metro reduziu o número de vagens por planta, embora Carvalho et al. (1998) tenha observado no cultivar Carioca (tipo III) aumento no número de vagens por planta no espaçamento de 0,60 m.

O número de grãos por vagem (Tabela 4), não foi influenciado significativamente, provavelmente por ser uma característica varietal pouco influenciada pelo ambiente, de alta herdabilidade e, portanto mais relacionada com as cultivares analisadas (ANDRADE et al., 1998). No entanto, Arf et al. (2004) observaram que o número de sementes por vagem foi influenciado pelas doses de $\mathrm{N}$ aplicadas em cobertura, indicando que uma melhor nutrição em $\mathrm{N}$ pode aumentar o número de óvulos fertilizados por vagem, o que poderia refletir em maior número de sementes.

Houve diferença estatística significativa para o espaçamento entrelinhas em relação ao número de grãos por vagem para a cultivar Pérola (Tabela 4). Sendo que o espaçamento de 0,60 m apresentou maior número de grãos por vagem em relação ao espaçamento de $0,50 \mathrm{~m}$. Apesar da diferença significativa observada, não há como considerar diferença entre 4,78 e 5 grãos por vagem.

Cultura Agronômica, Ilha Solteira, v.27, n.2, p.190-204, 2018 
Verifica-se na tabela 6, o desdobramento da interação significativa para massa de 100 grãos. Para o espaçamento de $0,50 \mathrm{~m}$ os dados se ajustaram a uma equação quadrática $\mathrm{y}=$ $24,13+0,038 \mathrm{x}-0,00024 \mathrm{x}^{2}\left(\mathrm{R}^{2}=0,81\right)$ atingindo um máximo com a dose de 79,2 $\mathrm{kg} \mathrm{ha}^{-1} \mathrm{de}$ nitrogênio. Para o espaçamento de $0,60 \mathrm{~m}$ os dados se ajustaram a uma equação quadrática $\mathrm{y}=23,84+0,047 \mathrm{x}-0,00027 \mathrm{x}^{2}\left(\mathrm{R}^{2}=0,67\right)$ atingindo um máximo com a dose de $87,0 \mathrm{~kg}$ ha ${ }^{-1}$ de nitrogênio.

Tabela 6. Desdobramento da interação significativa entre espaçamentos entrelinhas x doses de nitrogênio em cobertura para massa de 100 grãos (g) de feijoeiro cultivar Pérola.

\begin{tabular}{ccccccc}
\hline & \multicolumn{6}{c}{ Doses de Nitrogênio $\left(\mathrm{kg} \mathrm{ha}^{-1}\right)$} \\
\cline { 2 - 7 } Espaçamento $(\mathrm{m})$ & 0 & 35 & 70 & 105 & 140 & \\
\hline 0,4 & $25,79 \mathrm{a}$ & $26,07^{\mathrm{a}}$ & $25,90 \mathrm{a}$ & $24,03 \mathrm{~b}$ & $26,02 \mathrm{a}$ & $\mathrm{ns}$ \\
0,5 & $24,26 \mathrm{~b}$ & $24,96 \mathrm{~b}$ & $25,43 \mathrm{a}$ & $25,95 \mathrm{a}$ & $24,57 \mathrm{~b}$ & $\mathrm{RQ}^{* *}$ \\
0,6 & $23,90 \mathrm{~b}$ & $25,24 \mathrm{ab}$ & $25,10 \mathrm{a}$ & $26,53 \mathrm{a}$ & $24,73 \mathrm{~b}$ & $\mathrm{RQ}^{* *}$ \\
\hline DMS 1,01 & \multicolumn{7}{c}{} & & & &
\end{tabular}

Médias seguidas da mesma letra minúscula na coluna não diferem entre si pelo teste de tukey ao nível de 5\% de probabilidade. ${ }^{* *} \mathrm{p}<0,01 \mathrm{e}{ }^{\text {ns }}$ não significativo. $\mathrm{RQ}=$ regressão quadrática.

Para o desdobramento espaçamento entrelinhas dentro de doses de $\mathrm{N}$ observa-se que de maneira geral o menor espaçamento $(0,40 \mathrm{~m})$ apresentou maior valor de massa de 100 grãos na maioria das doses de nitrogênio utilizadas. Resultados discordantes de Arf et al. (1992) que verificaram em plantas do tipo III uma tendência dos menores espaçamentos produzirem na media sementes com menor peso

Houve interação significativa para massa de 100 grãos entre espaçamentos entrelinhas e doses de nitrogênio em cobertura para a cv Juriti e o desdobramento está apresentado na Tabela 7.

Tabela 7. Desdobramento da interação significativa entre espaçamentos entrelinhas x doses de nitrogênio em cobertura para massa de 100 grãos de feijoeiro cultivar Juriti.

\begin{tabular}{ccccccc}
\hline & \multicolumn{6}{c}{ Doses de Nitrogênio $\left(\mathrm{kg} \mathrm{ha}^{-1}\right)$} \\
\cline { 2 - 7 } Espaçamento (m) & 0 & 35 & 70 & 105 & 140 & \\
\hline 0,4 & $21,91 \mathrm{ab}$ & $24,47^{\mathrm{a}}$ & $22,55 \mathrm{a}$ & $22,18 \mathrm{~b}$ & $21,84 \mathrm{ab}$ & $\mathrm{RQ}^{* *(5)}$ \\
0,5 & $22,42 \mathrm{a}$ & $22,71 \mathrm{~b}$ & $22,77 \mathrm{a}$ & $23,82 \mathrm{a}$ & $22,96 \mathrm{a}$ & $\mathrm{RL}^{* *(6)}$ \\
0,6 & $20,87 \mathrm{~b}$ & $21,50 \mathrm{~b}$ & $22,04 \mathrm{a}$ & $21,68 \mathrm{~b}$ & $20,90 \mathrm{~b}$ & $\mathrm{RQ}^{* *}$ \\
\hline
\end{tabular}

\section{DMS 1,46}

Médias seguidas da mesma letra minúscula na coluna não diferem entre si pelo teste de tukey ao nível de 5\% de probabilidade. ${ }^{* *} \mathrm{p}<0,01$. $\mathrm{RL}=$ regressão linear $\mathrm{RQ}=$ regressão quadrática. ${ }^{(5)} \mathrm{y}=22,47+0,028 \mathrm{x}-$ $0,00025 \mathrm{x}^{2}\left(\mathrm{R}^{2}=0,40\right){ }^{(6)} \mathrm{y}=22,50+0,0062 \mathrm{x}\left(\mathrm{r}^{2}=0,42\right)$

Pelos dados da cultivar Juriti (Tabela 7) verifica-se que nos espaçamentos de 0,40 e $0,50 \mathrm{~m}$ apesar da significância para a interação, não mostraram um bom ajuste, com coeficiente de determinação muito baixo, sendo este coeficiente de 0,40 e 0,42 respectivamente, com ajuste a uma função quadrática e linear respectivamente. Para o 
espaçamento de $0,60 \mathrm{~m}$ os dados se ajustaram a uma equação quadrática $\mathrm{y}=20,82+0,031 \mathrm{x}$ - $0,00022 \mathrm{x}^{2}\left(\mathrm{r}^{2}=0,97\right)$ atingindo um máximo com a dose de $70,45 \mathrm{~kg} \mathrm{ha}^{-1}$ de nitrogênio.

Para o desdobramento espaçamento entrelinhas dentro de doses de $\mathrm{N}$ observa-se que de maneira geral o maior espaçamento $(0,60 \mathrm{~m})$ apresentou menor valor na massa de 100 grãos na maioria das doses de $\mathrm{N}$ utilizadas, talvez pela maior competição entre plantas na linha, já que a população de plantas por área era a mesma nos três espaçamentos utilizados. Arf et al. (1996) não verificaram efeito do espaçamento na massa de 100 para cultivar do tipo II.

Pelos resultados obtidos para produtividade de grãos (Tabela 4), verifica-se que houve efeito significativo para espaçamento e doses de $\mathrm{N}$ em cobertura para ambas as cultivares analisadas (Pérola e Juriti). Em relação aos espaçamentos entrelinhas, verifica-se que o menor espaçamento entrelinhas $(0,40 \mathrm{~m})$, proporcionou a maior produtividade $(4105 \mathrm{~kg} \mathrm{ha}$ $\left.{ }^{1}\right)$ para a cultivar Pérola. Em relação a cultivar Juriti o espaçamento de 0,40 m (3243 $\left.\mathrm{kg} \mathrm{ha}^{-1}\right)$ e $0,50 \mathrm{~m}$ (2739 $\left.\mathrm{kg} \mathrm{ha}^{-1}\right)$ não diferiram entre si em relação à produtividades. Os resultados mostram-se similares aos encontrados por Faria e Krantz (1982) que obteve maiores produtividades de feijão irrigado utilizando o espaçamento de $0,50 \mathrm{~m}$ para o cultivar Aroana (tipo II) e 0,40 m para o Carioca (tipo III) e por Del Peloso (1990) utilizando o espaçamento de 0,30 m para o cultivar EMGOPA 201 Ouro (tipo II) e 0,40 m para o Carioca (tipo III) e discordantes em dos obtidos por Almeida et al. (1975),que observaram que cultivares de hábito de crescimento indeterminado tipo III, prostradas, há uma tendência de obtenção de maiores produtividades em espaçamentos maiores.

Independentemente dos espaçamentos utilizados observa-se que as maiores médias de produtividade foram encontradas para a cultivar Pérola em relação a cultivar Juriti, isto pode ser possível devido ao seu hábito de crescimento que fecha mais rápido as entrelinhas, provocando um estiolamento das plantas que resulta em maior crescimento que pode ser verificado pelo maior número de ramos e consequentemente maior produtividade (ROCHA, 1991).

No que refere à aplicação de $\mathrm{N}$ em cobertura, ambas as cultivares se ajustaram a uma função linear $\mathrm{y}=2754,88+6,17 \mathrm{x}\left(\mathrm{r}^{2}=0,92\right)$ para a cultivar Pérola e $\mathrm{y}=2313,56+4,22 \mathrm{x}\left(\mathrm{r}^{2}=\right.$ $0,69)$ para a cultivar Juriti, demonstrando que o aumento de $\mathrm{N}$ em cobertura propiciou aumento na produtividade de sementes. Estes resultados estão de acordo com os obtidos por Costa et al. (2009) que observaram acréscimos no rendimento de grãos de feijão Pérola (tipo III) com a aplicação de doses crescentes de N. Gomes Junior et al. (2008) em sistema plantio direto sobre resíduos de milho obtiveram resposta linear da produtividade do feijão Juriti (tipo II).

As respostas antagônicas encontradas nos trabalhos com os cultivares do tipo II e III podem ser explicadas em função dos diferentes genótipos utilizados. Outro fator a ser levado em consideração são as diferentes condições de cultivo, as quais podem fazer variar o desempenho agronômico de um mesmo material.

Cultura Agronômica, Ilha Solteira, v.27, n.2, p.190-204, 2018 


\section{CONCLUSÃO}

$\mathrm{O}$ espaçamento de $0,40 \mathrm{~m}$ entrelinhas proporciona maior produtividade de grãos em ambas as cultivares analisadas (tipo II e III), quando se mantêm a população de plantas indicada para o habito de crescimento.

$\mathrm{O}$ fornecimento de doses crescentes de nitrogênio em cobertura proporciona aumento na produtividade em ambas as cultivares estudadas (tipo II e III).

\section{REFERÊNCIAS BIBLIOGRÁFICAS}

ALMEIDA, L. D'. A.; BULISANI, E. A.; MIYASAKA, S.; SORDI, G.; ALOISI SOBRINHO, J.; ALVES, S. Efeito da incorporação da massa vegetal, da adubação e do espaçamento, na produção do feijoeiro. Bragantia, Campinas, v. 34, n. 1, p. 43-47, 1975.

AMBROSANO, E. J.; TANAKA, R. T.; MASCARENHAS, H. A. A.; QUAGGIO, J. A.; CANTARELLA, H. Leguminosas e oleaginosas. In: VAN RAIJ, B.; CANTARELLA, H.; QUAGGIO, J. A. Recomendações de adubação e calagem para o Estado de São Paulo. 2.ed. Campinas: IAC, 1997. cap. 19, p. 189-203. (Boletim Técnico, 100).

ANDRADE, M. J. B.; DINIZ, A. R.; CARVALHO, J. G.; LIMA, S. F. Resposta da cultura do feijoeiro à aplicação foliar de molibdênio e às adubações nitrogenadas de plantio e cobertura. Ciência e Agrotecnologia, Lavras, v. 22, n.4, p.499-508, 1998. Disponível em: <http://periodicos.uem.br/ojs/index.php/ActaSciAgron/article/viewFile/1927/1234〉. Acesso em: 20 set. 2009.

ARF, O.; BUZETTI, S.; SÁ, M.E.; TOLEDO, A. R. M.; OLIVEIRA, C. A. G.; FUJIWARA, R. H.; ROMEIRO, P. J. M.; GUEIRREIRO NETO, G. Efeito de diferentes espaçamentos e densidades sobre os componentes produtivos do feijão (Phaseolus vulgaris L.) adubado em função da área e do espaçamento entre linhas. Cultura Agronômica, Ilha Solteira, v. 1, n. 1, p.1-10, 1992.

ARF, O., SÁ, M. E.; OKITA, C. S.; TIBA, M. A.; GUERREIRO NETO, G.; OGASAWARA, F. Y. Efeito de diferentes espaçamentos e densidades de semeadura sobre o desenvolvimento do feijoeiro (Phaseolus vulgaris L.). Pesquisa Agropecuária Brasileira. Brasília, v. 31, n. 9, p. 629-634, 1996. Disponível em: <https://seer.sct.embrapa.br/index.php/pab/article/view/4530>. Acesso em: 22 set. 2009.

ARF, O.; RODRIGUES, R. A. F.; SÁ, M. E.; BUZETTI, S.; NASCIMENTO, V. Manejo do solo, água e nitrogênio no cultivo de feijão. Pesquisa Agropecuária Brasileira, Brasília, v. 39, n.2, p.131-138, 2004. Disponível em: <http://www.alice.cnptia.embrapa.br/bitstream/doc/110074/1/Manejo.pdf >. Acesso em: 25 set. 2009.

BARBOSA FILHO, M. P.; SILVA, O. F. Adubação e calagem para o feijoeiro irrigado em solo de cerrado. Pesquisa Agropecuária Brasileira, Brasília, v. 35, n.7, p.1317-1324,

Cultura Agronômica, Ilha Solteira, v.27, n.2, p.190-204, 2018 
2000. Disponível em: <http://www.scielo.br/scielo.php?script=sci_arttext\&pid=S0100204X2000000700005>. Acesso em: 20 out. 2009.

CARVAlHO, M. A. C.; ARF, O.; SÁ, M. E. Efeito de espaçamentos e épocas de semeadura sobre o desempenho do feijão: I. Produção de sementes. Revista Brasileira de Sementes, Brasília, v. 20, n. 1, p.195-201, 1998.

CENTURION, J.F. Balanço hídrico da região de Ilha Solteira. Científica, Botucatu, v. 10, n. 1, p.57-61, 1982.

COELHO, F. C.; FREITAS, S. P.; MONERAT, P. H.; DORNELLES, M. S. Efeitos sobre a cultura do feijão das adubações com nitrogênio e molibdênio e do manejo de plantas daninhas. Revista Ceres, Viçosa, v. 48, n. 278, p. 455-467, 2001. Disponível em: <http://www.ceres.ufv.br/ojs/index.php/ceres/article/view/2981/831>. Acesso em: 22 out. 2009.

COSTA, R. S. S.; ARF, O.; ORIOLI JUNIOR, V.; BUZETTI, S. População de plantas e nitrogênio para feijão cultivado em sistema plantio direto. Revista Caatinga, Mossoró, v. 22, n. $\quad 4, \quad$ p.39-45, 2009. Disponível em: <https://periodicos.ufersa.edu.br/revistas/index.php/sistema/article/view/734/735>. Acesso em: 20 out. 2009.

CUNHA, P. C. R.; SILVEIRA, P. M.; XIMENES, P. A.; SOUZA, R. F.; ALVES JUNIOR, J.; NASCIMENTO, J. L. Fontes, formas de aplicação e doses de nitrogênio em feijão irrigado sobre plantio direto. Pesquisa Agropecuária Tropical, Goiânia, v. 41, n. 1, p.8086, 2011. Disponível em: <https://www.embrapa.br/busca-de-publicacoes//publicacao/882296/fontes-formas-de-aplicacao-e-doses-de-nitrogenio-em-feijoeiroirrigado-sob-plantio-direto>. Acesso em: 22 out.2009.

DEL PELOSO, M. J. Estudo de população de plantas na cultura do feijoeiro de inverno no Estado de Goiás. In: REUNIÃO SOBRE FEIJÃO IRRIGADO (GO, DF, MG, ES, SP, RJ), 1, 1988, Goiânia. Anais... Goiânia: EMBRAPA-CNPAF, 1990. p. 85-86. (Documentos, 27).

DOURADO NETO, D.; FANCELli, A. L. Produção de feijão. Guaíba: Agropecuária, 2000. 385 p.

EMPRESA BRASILEIRA DE PESQUISA AGROPECUÁRIA - EMBRAPA. Sistema brasileiro de classificação de solos. Rio de Janeiro: Centro Nacional de Pesquisa de Solos, 2006. 306 p.

FERNANDEZ, F.; GEPTS, P.; LÓPEZ, M. Etapas de desarrollo en la planta de fríjol. In: LÓPEZ, M.; FERNÁNDEZ, F.; SCHOONHOVEN, A. VAN, (Ed.) Frijol: investigación y producción. Cali: CIAT, 1985. p. 61-78.

FERREIRA, D. F. SISVAR: Um programa para análises estatísticas e ensino de estatística. Revista Symposium, v. 6, n. 1, p.36-41, 2008.

Cultura Agronômica, Ilha Solteira, v.27, n.2, p.190-204, 2018 
FRONZA, V. Resposta de cultivares de feijão (Phaseolus vulgaris L.) de porte ereto a espaçamentos entrelinhas e níveis de adubação. Revista Ceres, Viçosa, v. 41, n. 235, p.317326, $1994 . \quad$ Disponivel em: <http://www.ceres.ufv.br/ojs/index.php/ceres/article/viewFile/2105/150>. Acesso em: 25 nov. 2009.

GOMES JÚNIOR, F. G.; SÁ, M. E.; VALÉRIO FILHO, W. V. Nitrogênio no feijoeiro em sistema de plantio direto sobre gramíneas. Acta Scientiarum: agronomy, Maringá, v. 30, n. $3, \quad$ p.387-395, 2008. Disponivel em: <http://periodicos.uem.br/ojs/index.php/ActaSciAgron/article/view/3549>. Acesso em: 20 nov. 2009.

MALAVOLTA, E.; VITTI, G. C.; OLIVEIRA, S. A. Avaliação do estado nutricional das planta: princípios e aplicações. Piracicaba: POTAFOS, 1997. 319 p.

MASCARENHAS, H. A. A.; TANAKA, R. T. Soja. In: RAIJ, B. VAN; CANTARELLA, H.; QUAGGIO, J. A.; FURLANI, A. M. C. (Ed.). Recomendações de adubação e calagem para o Estado de São Paulo. 2. ed. Campinas: IAC / FUNDAG, 1997. p. 202-203.

MORAIS, L. K.; CARBONELL, S. A. M.; PINHEIRO, J. B.; JUNIOR FONSECA, N. S.; BRASIL, E. M. Avaliação de cultivares de feijoeiro, Phaseolus vulgaris L., sob diferentes espaçamentos. Acta Scientiarum, Maringá, v. 23, n. 5, p.1199-1203, 2001. Disponível em: $<$ https://www.researchgate.net/profile/Jose_Pinheiro3/publication/277125139_Avaliacao_d e_cultivares_de_feijoeiro_Phaseolus_vulgaris_L_sob_diferentes_espacamentos/links/55b12 52c08ae9289a084c9ed.pdf?origin=publication_detail>. Acesso em: 20 nov. 2009.

NIENHUIS, J.; SINGH, S. P. Effects of location and plant density on yield and architectural traits in dry beans. Crop Science, Madison, v. 25, n. 4, p.579-584, 1985.

PORTES, T. A. Ecofisiologia. In: ARAUJO, R. S.; RAVA, C. A.; STONE, L. F.; ZIMMERMANN, M. J. O. (Coord.). Cultura do feijoeiro comum no Brasil. Piracicaba: Potafós, 1996. p. 101-131.

ROCHA, J. A. M. Produção do feijoeiro (Phaseolus vulgaris L.) cultivado em populações variáveis quanto ao número e ao arranjamento de planta. 1991. $48 \mathrm{f}$. Dissertação (Mestrado em Agronomia) - Escola Superior de Agricultura Luiz de Queiroz, Universidade de São Paulo, Piracicaba, 1991.

ROSOLEM, C. A. Nutrição e adubação do feijoeiro. Piracicaba: Potafos, 1987. 93 p. (Boletim Técnico, 8).

SHIMADA, M. M.; ARF, O.; SÁ, M. E. Componentes do rendimento e desenvolvimento do feijoeiro de porte ereto sob diferentes densidades populacionais. Bragantia, Campinas, v. 59, n. 2, p.181-187, 2000. Disponível em: <http://www.scielo.br/scielo.php?pid=S000687052000000200009\&script=sci_abstract\&tlng=pt>. Acesso em: 10 nov. 2009.

SILVEIRA, P. M.; DAMASCENO, M. A. Doses e parcelamentos de K e N na cultura do feijoeiro irrigado. Pesquisa Agropecuária Brasileira, Brasília, v. 28, n. 11, p.1269-1276,

Cultura Agronômica, Ilha Solteira, v.27, n.2, p.190-204, 2018 
1993.

<http://ainfo.cnptia.embrapa.br/digital/bitstream/item/126198/1/pab2.pdf >. Acesso em: 20 out. 2009.

TEIXEIRA, I. R.; ANDRADE, M. J. B.; CARVALHO, J. G.; MORAIS, A. R.; CORRÊA, J. B. D. Resposta do feijoeiro (Phaseolus vulgaris L. cv. pérola) a diferentes densidades de semeadura e doses de nitrogênio. Ciência e Agrotecnologia, Lavras, v. 24, n. 2, p.399-408, 2000 . 